\title{
Analysis of heart rate variability during head-up tilt-test in patients with vasovagal syncope
}

\author{
Szymon Budrejko, Maciej Kempa $\odot$, Monika Chmielecka, \\ Dariusz Kozłowski $\odot$, Grzegorz Raczak $\odot$
}

Department of Cardiology and Electrotherapy, Medical University of Gdańsk, Poland

\begin{abstract}
Introduction: Syncope is defined as transient loss of consciousness, due to decrease in brain perfusion. The most frequent mechanism is vasovagal syncope. In many patients, the cause of syncope remains unspecified, despite an extensive diagnostic work-up. Tilt-test (TT) is an acknowledged diagnostic tool for syncope. Currently, the so-called Italian protocol of TT is most widely used. Vasovagal syncope is caused by impaired circulatory regulation in response to orthostatic stress. One of the available tools to examine the influence of the nervous system on the circulation is the analysis of heart rate variability (HRV). Despite numerous publications concerning HRV parameters and autonomic regulation in patients with syncope, direct comparisons and metaanalysis of the results is impossible, due to variability of TT protocols and study group specifications. Aim of the study: As there is no uniform model of HRV during TT, we aimed to analyze HRV parameters during TT (performed according to the Italian protocol) in patients with vasovagal syncope, in order to determine the possible application of HRV measurements in clinical practice in that group of patients. Detailed objectives were: (1) analysis and comparison of HRV in patients with and without the history of syncope; (2) analysis of HRV changes in consecutive stages of TT; (3) identification of possible HRV differences between patients with positive and negative TT results. Material and methods: Patients between 18 and 50 years of age were qualified for the study, if they had a history of at least 2 incidents of syncope or presyncope within the preceeding 6 months, and if signs and symptoms indicated the vasovagal mechanism. The study group included 150 patients: 100 consecutive patients with a postive TT result (POS), and 50 consecutive patients with a negative TT result (NEG). The control group (CG) comprised 50 volunteers with no history of syncope nor presyncope, matched according to age and sex to the study group. In all patients a TT was performed according to the Italian protocol, with paced breathing at a rate of $15 / \mathrm{min}$. Time-domain (meanRR, SDNN, RMSSD, pNN50) and frequency-domain (abs_LF, abs_HF, rel_LF, rel_HF, norm_LF, norm_HF, LF/HF) HRV parameters were analyzed and compared at different stages of TT in the study groups as specified above. Results: 100 patients at the age of $18-44$ years were included in the POS group, 50 patients at the age of 18-39 years in the NEG group, and 50 volunteers at the age of 20-39 in the CG. Volunteers in the control group developed unexpectedly high percentage of positive TT (14 patients). For consistency of analysis, the CG was thus subdivided according to the result of the TT into CG_POS (positive result of TT) -14 patients, and CG_ NEG (negative result of TT) - 36 patients. Based on HRV analaysis, no significant differences in HRV values were noted between patients with a history of syncope and positive or negative result of TT. Upright tilt resulted in HRV changes of the same direction and value in syncopal patients in the POS and NEG goup, as well as in patients in the CG_NEG group. Conclusion: HRV values and changes of those values at subsequent stages of TT were not different between syncopal patients with postive or negative TT result, or negative TT control group. The Italian protocol of TT may be associated with a surprisingly high percentage of false positive results.
\end{abstract}

Keywords: tilt table test $\bullet$ syncope $\bullet$ vasovagal syncope $\bullet$ heart rate variability 


\section{Citation}

Budrejko S, Kempa M, Chmielecka M, Kozłowski D, Raczak G. Analysis of Heart Rate Variability During Head-Up Tilt-Test in Patients with Vasovagal Syncope. Eur J Transl Clin Med 2018;1(1):24-38.

DOI: $10.31373 /$ ejtcm/92837

\section{Introduction}

According to the current definition by the the European Society of Cardiology (ESC), syncope is a transient loss of consciousness, due to transient hypoperfusion of the central nervous system, and is characterised by abrupt onset, short duration and spontaneous complete recovery [1]. Syncope is associated with loss of tension of postural muscles, and it results in falling down. Syncope may or may be not be preceeded by presyncopal symptoms. It usually lasts approximately 20 seconds, and recovery does not require any additional medical interventions.

Syncope is a serious individual problem of the affected patients and a common cause of emergency department visits and hospital admissions [1-6]. Diagnosis of syncope is associated with remarkably high costs to the healthcare system [7]. The median age of the onset of syncope is 25 years, and in every age group the incidence of syncope is higher in women than men [8-9].

According to the literature, the dominant cause of syncope is reflex syncope and its particular type - vasovagal syncope [10-11]. The remaining causes are: cardiac syncope $(9,5 \%)$ and orthostatic syncope $(9,4 \%)$. Vasovagal syncope is associated with good prognosis and zero cardiovascular mortality [12]. Nonetheless, it is troublesome for patients, as it is recurrent in $7-33 \%$ [13-15].

The participation of cardiac and vascular components in brain hypoperfusion leading to syncope is different in various types of syncope. Based on that, syncope may be reflex (with the dominant vasovagal group), orthostatic or cardiovascular [1].

Vasovagal syncope may be further subdivided into several types, according to the type of hemodynamic response observed during tilt table test (TT). Currently, the modified VASIS classification is in use [16]. The types of hemodynamic response are as follows:

- type 1 (VVS 1), mixed type: heart rate (HR) does not slow down $<40 \mathrm{bpm}$, or it does for $<10 \mathrm{sec}-$ onds,

- type 2 (VVS 2), cardioinhibitory type:

○ type $2 \mathrm{~A}$ - without asystole (HR below $40 \mathrm{bpm}$ for more than 10 seconds, but no asystole $>3$ seconds),

O type $2 \mathrm{~B}$ - with asystole (asystole $>3$ seconds),

- type 3 (VVS 3), vasodepressive type: HR during syncope does not decrese by more than $10 \%$.
The mechanism of vasovagal reaction is based on the imbalance of the autonomic nervous system and its influence over cardiovascular regulation. Orthostatic stress leads to transient hyperactivity of the sympathetic influence, but then hypotension and bradycaria occur due to sudden drop of sympathetic tone and increase of parasympathetic activation [17]. It leads to brain hypoperfusion and loss of consciousness. Unfortunately, the afferent mechanism leading to that reflex remains unknown [18-20].

Vasovagal syncope is diagnosed, when the loss of consciousness is preceeded by emotional stress or orthostatic stress, and is associated with typical prodromal symptoms. The next diagnostic step may include the tilt table test, which allows to induce and document vasovagal reflex in controlled clinical conditions [21-25]. Currently the most popular protocol of the test is the Italian protocol. It requires 20 minutes of passive test in the upright position, followed by the active phase with $400 \mu \mathrm{g}$ of nitroglycerin adminstered sublingually [18, 26-27].

The diagnostic value of TT is mostly appreciated in atypical cases of vasovagal syncope, when other causes of syncope been excluded. The majority of tests are performed in case of single syncopal episode in a high-risk setting (trauma or professional indications) or in case of recurrent episodes in patients without any organic heart disease. TT is a safe diagnostic tool, no serious complications have been reported.

The influence of autonomic nervous system (ANS) on the heart is expressed not only as the momentary heart rate, but also as heart rate variability (HRV). Methods of HRV analysis include time domain measurements, spectral analysis and nonlinear analysis. Time domain parameters include: SDNN (standard deviation of the NN interval ${ }^{1}$ ), SDANN (standard deviation of the average NN interval), SDNN index (SDNNi), RMSSD (square root of the mean squared differences of successive NN intervals), NN50 and pNN50. RMSSD and pNN50 are indices of short term variability and correlate well with the power of high frequency domain [28-29]. Spectral analysis presents the distribution of spectral power of heart rate variabilty (consistent with total variance) as a fuction of frequency. Values are presented as spectral amplitude units (ms), spectral power $\left(\mathrm{ms}^{2}\right)$ or power spectral density $\left(\mathrm{ms}^{2} / \mathrm{Hz}\right)$. Spectral analysis may be performed

${ }^{1}$ Defined as a normal RR interval of sinus origin. 
with fast Fourier transform or (FFT) or autoregression [28]. Spectral analysis may determine the following parameters: TP (total power); VLF (very low frequency) $(\leq 0,04 \mathrm{~Hz})$; LF (low frequency) $(0,04-0,15 \mathrm{~Hz})$; LFnu (LF normalized units) - LF n.u. = LF/(TP-VLF) $\times 100$; HF (high frequency) - (0,15-0,4 Hz); HFnu (HF normalized units) - HF n.u. = HF/(TP-VLF) x 100; and finally LF/HF. Spectral analysis allows to determine relations and balance of both parts of ANS, but absolote values of HRV parameters are not measures of absolute activity of ANS. It is accepted, that HF domain is associated mainly with parasympathetic modulation, whereas LF domain is driven mostly by sympathetic modulation. LF/HF ratio may be used as the approximation of balance of the influence of both parts of ANS on the heart.

Attempts to use the HRV method in vasovagal syncope date back to the 1990s. No clear association was found between HRV measured in long-term recordings and syncope [30-36]. Many studies were devoted to HRV analysis during TT in patients with vasovagal syncope. But as TT protocols, timings and pharmacological provocation schemes evolved in time, and authors used various patterns of subdivision into study groups, no clear pattern of analysis of HRV parameters in that clinical setting was determined [25, 33, 37-62]. Similarly, no practical use of HRV analysis during TT is available.

\section{Aim of the study}

For the reasons stated above, we attempted to analyse HRV parameters during tilt table test (performed according to the Italian protocol) in patients with vasovagal syncope, to determine the possible practical use of HRV values in that clinical setting. Specifically, we aimed to compare HRV values in patients with and without history of syncope, in predefined groups, and analyze HRV values during consecutive stages of TT.

\section{Material and methods}

The study was approved by the Independent Bioethical Committee at the Medical University of Gdansk. Funding was provided from research budget of the Department of Cardiology and Electrotherapy. Study group was recruited from patients with a history of syncope/presyncope (S/P) consulted in the Outpatient Syncope Unit. The history was collected according to a standard, detailed form. Initial diagnosis of vasovagal syncope (VVS) was made on the basis of typical provocative factors, signs and symptoms. Then, the physical examination and ECG were performed. If other causes of syncope were syspected, patients underwent additional examinations, accordingly.

The inclusion criteria were as follows: the history of at least 2 incidents of S/P during ppreceeding 6 months, history typical for VVS, no evidence of other possible causes of S/P in history and physical examination, age between 18 and 50 years.

The exclusion criteria were: other susppected cause of $S / P$, age below 18 or above 50 years, arrhythmias rendering the analysis of HRV impossible (leading rhythm other than sinus, frequent supraventricular or ventricular extrasystolic beats) and lack of patient's consent.

All patients signed an informed consent to participate in the analysis. The study group included 150 patients, and was divided into two subgroups: (1) 100 consecutive patients with a history of $S / P$, meeting the above criteria, with a positive result of TT ('positive' group - POS); (2) 50 consecutive patients with a history of $S / P$, meeting the above criteria, with a negative result of TT ('negative' group - NEG). The control group (CG) included 50 volunteers with no history of $S / P$, no history of cardiac disease (including hypertension and arrhythmias), no cardiovascular abnormalities in physical examination, not takin any drugs (excluding hormonal contraceptives in women), that gave their consent to participate in the study.

All 200 patients underwent TT. The test was performed in the TT laboratory in our department, according to the standard protocol (the Italian protocol). Patients were fasting 8 hours before TT, and did not consume drinks containing methyloxantine compound ${ }^{2}$ for 24 hours. Tilt table was equipped with foot support and safety belts. Cardiovascular parameters were monitored with the use of Task Force Monitor (CNSystems Medizintechnik $\mathrm{GmbH}$, Austria, software version 2.0.0.27). Blood pressure values and ECG beat-to-beat intervals were recorded. Recordings were started 20 minutes before the onset of orthostatic stress, and continued throughout the study, until at least 15 minutes after syncope and/or returning to the horizontal position. Time markers were recorded for future reference.

Patients were asked to follow a paced breathing pattern at 15 cycles per minute ( 1 cycle every 4 seconds, $f=0.25 \mathrm{~Hz}$ ), as dictated outloud by software of our own design.

Patients remained in horizontal position for at least 30 minutes following venipuncture, after that time the table was brought to more vertical position ( 60 degrees). That position was maintained for 20 minutes (passive test). Then, if the passive test was negative and there were no containdications, one sublingual dose of 400 micrograms of nitroglycerin (NTG) was administered (Nitromint, EGIS), and such active phase was maintained for 15 minutes or until syncope. The test was terminated and the patient brought back to horizontal position in case of S/P due to vasovagal reflex (positive test), in case of protocol completion without S/P (negative test),

\footnotetext{
2 Coffee, tea, so-called „energy drinks”
} 
or if that was any patient's will (inconclusive test). Recordings were then continued for at least 15 minutes. Type of vasovagal response were classified according to the ESC guidelines [1] and the modified VASIS classification [16].

Data of monitored parameters (ECG tracings and RR intervals, blood pressure values) were recorded as .fef files (file format of the Task Force Monitor). Then the tracings were visually verified. Numerical data of all the measurements, and specifically RR intervals were exported into MS Excel spreadsheets. Next, 5-minute series of RR intervals were extracted according to the prespecified time markers, and the following time intervals were analyzed: initial horizontal position before vertical tilt (_PRE), first 5 minutes of the passive test (_PO), next 5 minutes (between 5th and 10th minute - _P5), time between $10^{\text {th }}$ and $15^{\text {th }}$ minute (_P10), and between $15^{\text {th }}$ and $20^{\text {th }}$ minute (_P15) of the passive test, and then 5 minutes after final recovery to the horizontal position (_H). Data from the active test phase were not analized due to non-stationary behavior of cardiovascular parameters during that period. RR intervals were extracted as ASCII files, and imported into the program for HRV analysis (KUBIOS HRV v. 2.0, Biosignal Analysis and Medical Imaging Group from the University of Kuopio, Finland, licensed for the authors of that publication). All artifacts were corrected by appropriate algorhithms. HRV values were exported again into MS Excel files and recorded in a database, along with basic characteristics of patients. Derivant parameters were calculated, and thus for ex-

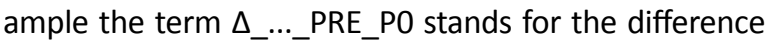
of the value between the time period PRE and PO.

The following time domain parameters were analyzed: minimal, maximal and mean heart rate, SDNN, RMSSD and pNN50. Spectral analysis was based on FFT method, and included the following parameters: absolute LF power (abs_LF, [ms ${ }^{2}$ ], 0.04-0.15 Hz), absolute HF power (abs_HF, $\left[\mathrm{ms}^{2}\right], 0.15-0.4 \mathrm{~Hz}$ ), relative LF (rel_LF, [\%], [LF/TP]x100\%, where TP = total power), relative HF
(rel_HF, [\%], [HF/TP]x100\%), LF power in normalized units (norm_LF, [n.u.], LF/[TP-VLF]x100), HF power in normalized units (norm_HF, [n.u.], HF/[TP-VLF]x100), and LF/HF ration.

All statistical analyses were performed with the use of Statistica $10 \mathrm{PL}$ (StatSoft), licensed for the Medical University of Gdansk. Descriptive statistics were presented as quantities and percentages, mean values and standard deviation, and median value, lower and upper quartile, maximal and minimal value, and interquartile range. W Shapiro-Wilk test was used to verify normal distribution of continuous variables. Uniformity of variance was verified with the $F$ test. In case of variables with normal distribution and uniform variances, values were compared with the use of t-Student test, for related or unrelated variables, as appropriate. In case of non-uniform variances, the Cochrane-Cox test was used. In case of non-normal distribution, data were compared with U Mann-Whitney test (unrelated variables) or Wilcoxon test (related variables). In order to evaluate differences among many groups of variables not fulfilling assumptions of the analysis of variance, and susch situation was noted in all configurations in our study, the Kruskal-Wallis ANOVA and appropriate post-hoc tests were used. Repeated measurements not fulfilling assumptions af the analysis of variance were analyzed with Friedmann ANOVA and post-hoc Dunn test. Borderline level of significance was set at $\alpha=0.05$. Computed probability lower than 0.05 were described as $p \leq 0.05, p \leq 0.01, p \leq 0001$, appropriately.

\section{Results}

Demographic data of the study groups are presented in table 1 . The percentage of women and men was not significantly different among groups. Patients in the CG group were taller than in POS and NEG groups. Body weight in the CG was significantly higher than in the POS group, but not body mass index (BMI).

Table 1. Demographic data of the study groups

\begin{tabular}{|c|c|c|c|c|}
\hline & POS & NEG & CG & $\mathbf{p}$ \\
\hline Number & 100 & 50 & 50 & - \\
\hline Percentage of men & $27 \%$ & $38 \%$ & $42 \%$ & ns \\
\hline Percentage of women & $73 \%$ & $62 \%$ & $58 \%$ & ns \\
\hline Age [years] & $18-44$ & $18-39$ & $20-39$ & - \\
\hline Mean age $\pm S D$ [years] & $26.1 \pm 7.4$ & $28.8 \pm 7.4$ & $24.3 \pm 5.0$ & ns \\
\hline Height $[\mathrm{cm}]$ & $152-196$ & $153-190$ & $160-196$ & - \\
\hline Mean height \pm SD $[\mathrm{cm}]$ & $169.0 \pm 9.0$ & $170.6 \pm 9.4$ & $176.1 \pm 8.7$ & $\mathrm{p}<0.001^{* \#}$ \\
\hline Weight [kg] & $45-95$ & 47-105 & $48-104$ & - \\
\hline Mean weight $\pm S D[\mathrm{~kg}]$ & $65.2 \pm 12.8$ & $70.1 \pm 15$ & $74.1 \pm 13.8$ & $\mathrm{p}<0.01^{\#}$ \\
\hline BMI $\left[\mathrm{kg} / \mathrm{m}^{2}\right]$ & $17.1-32.0$ & $16.6-33.2$ & $17.8-37.7$ & - \\
\hline Mean $\mathrm{BMI} \pm \mathrm{SD}\left[\mathrm{kg} / \mathrm{m}^{2}\right]$ & $22.7 \pm 3.3$ & $24.0 \pm 4.2$ & $23.8 \pm 3.7$ & ns \\
\hline
\end{tabular}

SD - standard deviation.* $p<0.05$ CG vs NEG; \# $p<0.05$ POS vs CG 
In the POS group, by definition, all TT were positive. There were 74 VVS- 1 and 26 VVS- 2 reactions. No patient presented type VVS-3 syncope. In 8 patients syncope occurred during the passive phase ( 6 VVS- 1 and 2 VVS$2)$. In the remaining 92 patients, the TT was positive in the active phase (68 VVS-1 and 24 VVS-2).

In the NEG group, by definition, TT was negative. In all patients both passive and active phases were performed.

In the CG, the TT was positive in an unexpectedly high number of patients - 14 (active test in all 14 cases). In the remaining 36 patients the complete TT protocol (passive and active) was negative. To maintain consistency of HRV analysis, the CG was therefore subdivided into postive TT group (CG_POS, 14 patients) and negative TT group (CG_NEG, 36 patients).

From the extensive HRV analysis and comparisons of subgropus in various combinations, we selected for the scope of this article only those apppropriate for the pre-defined aims of the study: mostly POS versus NEG, and the 'true negative' control group, i.e CG_NEG.

All numerical values of HRV parameters in all subgroups at consecutive stages of TT, as well as derivant parameters, are presented in table 2.

Table 2. Values of HRV parameters in all study groups

\begin{tabular}{|c|c|c|c|c|c|c|c|c|}
\hline & \multicolumn{2}{|c|}{ POS } & \multicolumn{2}{|c|}{ NEG } & \multicolumn{2}{|c|}{ CG_POS } & \multicolumn{2}{|c|}{ CG_NEG } \\
\hline & M & IQR & M & IQR & M & IQR & M & IQR \\
\hline & \multicolumn{8}{|c|}{ meanRR [ms] } \\
\hline PRE & 868,82 & 141,44 & 821,91 & 190,86 & 879,87 & 154,26 & 835,63 & 213,13 \\
\hline PO & 734,40 & 114,23 & 727,65 & 152,95 & 764,47 & 129,55 & 715,83 & 120,56 \\
\hline P5 & 719,36 & 126,67 & 722,59 & 137,31 & 733,39 & 142,12 & 717,20 & 138,39 \\
\hline P10 & 699,97 & 124,99 & 729,71 & 136,72 & 713,60 & 114,84 & 728,92 & 148,81 \\
\hline P15 & 697,07 & 119,55 & 719,00 & 128,11 & 700,42 & 122,69 & 722,07 & 131,72 \\
\hline $\mathrm{H}$ & 924,12 & 203,70 & 868,11 & 201,60 & 915,78 & 114,05 & 911,93 & 241,99 \\
\hline$\triangle$ DPO_PRE & $-132,72$ & 105,28 & $-108,18$ & 98,31 & $-120,82$ & 52,07 & $-100,34$ & 109,26 \\
\hline$\Delta \_P 15 \_P R E$ & $-163,95$ & 103,68 & $-118,96$ & 87,29 & $-162,35$ & 83,74 & $-110,11$ & 125,06 \\
\hline \multirow[t]{2}{*}{ D_P15_P0 } & $-29,64$ & 53,89 & $-3,75$ & 58,91 & $-24,29$ & 42,85 & $-10,12$ & 66,55 \\
\hline & \multicolumn{8}{|c|}{ SDNN [ms] } \\
\hline PRE & 63,27 & 34,07 & 59,86 & 35,07 & 53,43 & 24,55 & 57,27 & 40,67 \\
\hline PO & 48,58 & 22,15 & 44,66 & 29,35 & 50,93 & 22,48 & 62,08 & 26,97 \\
\hline P5 & 40,27 & 16,94 & 37,80 & 25,85 & 43,66 & 11,76 & 55,82 & 28,37 \\
\hline P10 & 44,42 & 19,71 & 40,16 & 26,48 & 45,62 & 11,49 & 54,74 & 29,16 \\
\hline P15 & 46,92 & 19,37 & 41,82 & 34,81 & 43,31 & 6,94 & 60,79 & 23,83 \\
\hline $\mathrm{H}$ & 94,93 & 53,67 & 72,42 & 46,93 & 64,02 & 26,20 & 79,69 & 70,99 \\
\hline$\Delta \_\mathrm{PO}$ _PRE & $-16,82$ & 22,29 & $-11,26$ & 29,25 & 0,82 & 20,32 & 0,30 & 36,33 \\
\hline$\Delta \_$P15_PRE & $-16,44$ & 29,39 & $-13,41$ & 25,17 & $-8,65$ & 16,82 & 0,65 & 36,68 \\
\hline \multirow[t]{2}{*}{$\Delta \_\mathrm{P} 15 \_\mathrm{P} 0$} & $-2,67$ & 17,66 & $-0,98$ & 14,99 & $-2,34$ & 26,46 & $-1,27$ & 25,94 \\
\hline & \multicolumn{8}{|c|}{ RMSSD [ms] } \\
\hline PRE & 45,92 & 27,85 & 37,24 & 45,97 & 38,71 & 30,29 & 50,67 & 47,21 \\
\hline PO & 22,68 & 12,38 & 25,34 & 12,75 & 27,21 & 11,56 & 31,85 & 19,61 \\
\hline P5 & 20,09 & 10,27 & 20,59 & 13,21 & 24,72 & 14,59 & 29,01 & 20,81 \\
\hline $\mathrm{P} 10$ & 20,30 & 9,58 & 22,17 & 17,25 & 26,20 & 15,61 & 30,63 & 23,45 \\
\hline P15 & 20,60 & 11,09 & 20,09 & 16,99 & 23,22 & 10,09 & 31,52 & 21,72 \\
\hline $\mathrm{H}$ & 61,99 & 47,68 & 41,36 & 60,89 & 55,70 & 21,56 & 70,83 & 90,59 \\
\hline$\triangle \_$PO_PRE & $-21,35$ & 25,10 & $-11,22$ & 29,94 & $-17,07$ & 21,87 & $-13,53$ & 47,80 \\
\hline D_P15_PRE & $-25,16$ & 27,47 & $-17,55$ & 28,79 & $-20,50$ & 21,90 & $-18,96$ & 43,96 \\
\hline$\Delta \_\mathrm{P} 15 \_\mathrm{P} 0$ & $-1,85$ & 8,06 & $-1,66$ & 7,68 & $-2,18$ & 6,00 & $-1,00$ & 11,61 \\
\hline
\end{tabular}




\begin{tabular}{|c|c|c|c|c|c|c|c|c|}
\hline \multirow[b]{2}{*}{ PRE } & \multicolumn{8}{|c|}{ pNN50 [\%] } \\
\hline & 22,47 & 27,69 & 14,19 & 35,11 & 17,35 & 24,76 & 27,74 & 33,33 \\
\hline $\mathrm{PO}$ & 3,16 & 7,42 & 5,33 & 7,28 & 3,69 & 7,41 & 10,25 & 15,41 \\
\hline P5 & 1,63 & 4,38 & 2,28 & 5,52 & 3,34 & 8,26 & 8,01 & 15,65 \\
\hline P10 & 2,53 & 4,11 & 2,69 & 8,11 & 4,58 & 6,88 & 7,14 & 18,85 \\
\hline P15 & 2,35 & 5,16 & 1,81 & 6,96 & 3,81 & 4,40 & 8,91 & 16,77 \\
\hline $\mathrm{H}$ & 30,81 & 30,60 & 15,77 & 35,14 & 29,58 & 24,82 & 38,38 & 43,13 \\
\hline$\triangle \_$PO_PRE & $-18,56$ & 27,33 & $-6,81$ & 26,39 & $-13,13$ & 16,38 & $-14,13$ & 29,37 \\
\hline$\Delta \_$P15_PRE & $-18,79$ & 23,70 & $-10,18$ & 28,05 & $-14,64$ & 21,72 & $-14,34$ & 32,54 \\
\hline \multirow[t]{2}{*}{$\Delta \_\mathrm{P} 15 \_\mathrm{P} 0$} & $-0,80$ & 3,67 & $-0,68$ & 3,84 & $-0,72$ & 5,77 & 0,00 & 7,14 \\
\hline & \multicolumn{8}{|c|}{ abs_LF $\left[\mathrm{ms}^{2}\right]$} \\
\hline PRE & 776,47 & 984,90 & 700,29 & 1222,66 & 581,67 & 578,50 & 859,55 & 1033,28 \\
\hline PO & 575,80 & 854,81 & 695,74 & 833,16 & 612,70 & 538,72 & 1339,70 & 1520,85 \\
\hline P5 & 496,09 & 548,11 & 611,23 & 792,11 & 738,19 & 563,24 & 1068,70 & 1251,58 \\
\hline P10 & 685,23 & 598,70 & 559,71 & 1060,97 & 796,22 & 733,39 & 1203,37 & 1607,28 \\
\hline P15 & 595,67 & 696,01 & 584,96 & 1127,24 & 696,67 & 444,43 & 1611,34 & 1687,78 \\
\hline $\mathrm{H}$ & 1381,61 & 1599,54 & 1074,08 & 2000,69 & 910,64 & 1536,57 & 1457,32 & 3729,13 \\
\hline$\Delta \_P O \_P R E$ & $-167,39$ & 820,51 & $-119,21$ & 621,09 & $-43,79$ & 450,94 & 314,04 & 1311,10 \\
\hline D_P15_PRE & $-136,51$ & 763,33 & $-77,78$ & 715,72 & 148,36 & 483,61 & 579,86 & 1812,19 \\
\hline \multirow[t]{2}{*}{$\Delta \_\mathrm{P} 15 \_\mathrm{P} 0$} & 17,32 & 534,86 & $-60,93$ & 458,47 & 178,66 & 512,67 & 179,90 & 1238,74 \\
\hline & \multicolumn{8}{|c|}{ abs_HF $\left[\mathrm{ms}^{2}\right]$} \\
\hline PRE & 761,31 & 1156,05 & 521,84 & 1733,23 & 711,18 & 966,52 & 924,34 & 1469,61 \\
\hline $\mathrm{PO}$ & 167,99 & 240,04 & 205,12 & 309,53 & 187,70 & 393,58 & 401,39 & 535,33 \\
\hline P5 & 159,74 & 207,50 & 145,84 & 250,24 & 241,57 & 338,42 & 355,73 & 611,58 \\
\hline P10 & 175,76 & 195,51 & 164,70 & 406,21 & 304,27 & 413,59 & 435,40 & 559,66 \\
\hline P15 & 152,12 & 184,22 & 174,24 & 316,59 & 290,97 & 290,43 & 398,46 & 500,34 \\
\hline $\mathrm{H}$ & 1209,04 & 2607,98 & 675,38 & 2997,14 & 1106,39 & 959,46 & 1771,46 & 4243,63 \\
\hline$\Delta \_P O \_P R E$ & $-541,63$ & 1169,93 & $-302,45$ & 1167,42 & $-433,68$ & 863,44 & $-399,02$ & 1083,84 \\
\hline D_P15_PRE & $-577,86$ & 1142,80 & $-374,24$ & 1123,01 & $-471,68$ & 707,64 & $-424,68$ & 1533,59 \\
\hline \multirow[t]{2}{*}{$\Delta \_P 15 \_P 0$} & $-1,91$ & 123,45 & $-1,11$ & 173,49 & $-14,98$ & 77,33 & $-11,41$ & 356,86 \\
\hline & \multicolumn{8}{|c|}{ rel_LF [\%] } \\
\hline PRE & 25,96 & 18,36 & 26,45 & 13,71 & 29,43 & 15,16 & 33,20 & 19,03 \\
\hline $\mathrm{PO}$ & 35,77 & 23,08 & 36,18 & 17,77 & 34,50 & 20,98 & 37,90 & 24,88 \\
\hline P5 & 37,15 & 18,65 & 33,35 & 27,49 & 44,40 & 23,07 & 44,74 & 21,22 \\
\hline P10 & 38,63 & 18,31 & 37,05 & 23,66 & 43,48 & 18,92 & 48,37 & 26,29 \\
\hline P15 & 40,09 & 20,72 & 38,73 & 26,06 & 48,70 & 16,34 & 47,63 & 16,23 \\
\hline $\mathrm{H}$ & 23,04 & 14,81 & 28,15 & 13,43 & 28,51 & 23,31 & 26,90 & 22,82 \\
\hline$\Delta$ DPO_PRE & 8,88 & 28,19 & 8,24 & 18,70 & 8,44 & 29,37 & 6,53 & 16,29 \\
\hline D_P15_PRE & 11,69 & 28,52 & 9,83 & 29,27 & 16,11 & 21,00 & 16,01 & 16,14 \\
\hline \multirow[t]{2}{*}{$\Delta \_P 15 \_P 0$} & 4,81 & 23,40 & 6,86 & 25,48 & 7,61 & 18,17 & 10,05 & 21,55 \\
\hline & \multicolumn{8}{|c|}{ rel HF [\%] } \\
\hline PRE & 24,69 & 23,32 & 20,21 & 25,70 & 37,36 & 23,85 & 35,18 & 20,61 \\
\hline PO & 8,71 & 10,02 & 9,60 & 13,33 & 14,23 & 13,41 & 14,05 & 12,61 \\
\hline P5 & 10,96 & 11,56 & 9,04 & 15,53 & 13,20 & 14,39 & 16,40 & 14,36 \\
\hline $\mathrm{P} 10$ & 9,08 & 8,02 & 9,83 & 8,82 & 12,63 & 12,23 & 13,82 & 11,72 \\
\hline P15 & 9,26 & 7,83 & 10,77 & 10,71 & 12,29 & 16,54 & 14,58 & 10,08 \\
\hline $\mathrm{H}$ & 18,04 & 24,05 & 21,07 & 23,20 & 26,16 & 25,38 & 32,83 & 31,13 \\
\hline$\Delta \_P O \_P R E$ & $-13,27$ & 20,94 & $-6,87$ & 15,49 & $-18,34$ & 10,82 & $-17,94$ & 20,89 \\
\hline D_P15_PRE & $-14,11$ & 20,37 & $-5,19$ & 24,45 & $-17,27$ & 13,07 & $-20,61$ & 20,01 \\
\hline$\Delta \_P 15 \_P 0$ & $-0,07$ & 6,76 & 0,57 & 8,73 & $-0,05$ & 4,83 & $-1,31$ & 11,66 \\
\hline
\end{tabular}




\begin{tabular}{|c|c|c|c|c|c|c|c|c|}
\hline \multirow[b]{2}{*}{ PRE } & \multicolumn{8}{|c|}{ norm_LF [n.u.] } \\
\hline & 56,58 & 28,22 & 56,57 & 31,15 & 48,22 & 31,15 & 46,11 & 24,08 \\
\hline $\mathrm{PO}$ & 79,01 & 16,69 & 78,12 & 17,05 & 71,22 & 12,23 & 75,37 & 20,85 \\
\hline P5 & 77,37 & 19,34 & 79,76 & 22,69 & 74,05 & 33,43 & 71,73 & 23,28 \\
\hline P10 & 80,30 & 16,06 & 77,55 & 21,51 & 80,27 & 28,62 & 74,94 & 14,42 \\
\hline P15 & 82,18 & 17,58 & 78,66 & 22,49 & 81,00 & 26,97 & 78,68 & 14,25 \\
\hline $\mathrm{H}$ & 55,38 & 24,73 & 57,15 & 33,76 & 49,10 & 37,10 & 44,22 & 28,81 \\
\hline$\triangle$ D_PO_PRE & 21,49 & 27,53 & 16,46 & 23,29 & 21,46 & 30,20 & 25,69 & 21,43 \\
\hline D_P15_PRE & 26,16 & 22,54 & 19,94 & 25,46 & 25,97 & 18,81 & 29,09 & 20,79 \\
\hline \multirow[t]{2}{*}{$\Delta \_\mathrm{P} 15 \_\mathrm{P0}$} & 0,22 & 10,77 & 1,26 & 10,31 & 6,53 & 8,56 & 4,98 & 11,64 \\
\hline & \multicolumn{8}{|c|}{ norm_HF [n.u.] } \\
\hline PRE & 43,42 & 28,22 & 43,43 & 31,15 & 51,78 & 31,15 & 53,89 & 24,08 \\
\hline $\mathrm{PO}$ & 20,99 & 16,69 & 21,88 & 17,05 & 28,78 & 12,23 & 24,63 & 20,85 \\
\hline P5 & 22,63 & 19,34 & 20,24 & 22,69 & 25,95 & 33,43 & 28,27 & 23,28 \\
\hline P10 & 19,70 & 16,06 & 22,45 & 21,51 & 19,73 & 28,62 & 25,06 & 14,42 \\
\hline P15 & 17,82 & 17,58 & 21,34 & 22,49 & 19,00 & 26,97 & 21,32 & 14,25 \\
\hline $\mathrm{H}$ & 44,62 & 24,73 & 42,85 & 33,76 & 50,90 & 37,10 & 55,78 & 28,81 \\
\hline$\Delta \_$P0_PRE & $-21,49$ & 27,53 & $-16,46$ & 23,29 & $-21,46$ & 30,20 & $-25,69$ & 21,43 \\
\hline$\Delta$ DP15_PRE & $-26,16$ & 22,54 & $-19,94$ & 25,46 & $-25,97$ & 18,81 & $-29,09$ & 20,79 \\
\hline \multirow[t]{2}{*}{$\Delta \_\mathrm{P} 15 \_\mathrm{P} 0$} & $-0,22$ & 10,77 & $-1,26$ & 10,31 & $-6,53$ & 8,56 & $-4,98$ & 11,64 \\
\hline & \multicolumn{8}{|c|}{ LF/HF } \\
\hline PRE & 1,30 & 1,53 & 1,30 & 2,01 & 0,93 & 1,09 & 0,86 & 0,88 \\
\hline $\mathrm{PO}$ & 3,76 & 4,60 & 3,58 & 4,04 & 2,47 & 1,89 & 3,06 & 2,99 \\
\hline P5 & 3,42 & 4,44 & 3,94 & 5,12 & 2,86 & 5,34 & 2,54 & 3,35 \\
\hline P10 & 4,08 & 4,11 & 3,45 & 4,66 & 4,09 & 6,14 & 3,00 & 2,24 \\
\hline P15 & 4,61 & 4,82 & 3,69 & 6,31 & 4,26 & 3,96 & 3,69 & 2,60 \\
\hline $\mathrm{H}$ & 1,24 & 1,34 & 1,34 & 2,52 & 0,97 & 2,30 & 0,79 & 1,02 \\
\hline$\Delta \_P 0 \_P R E$ & 2,35 & 5,00 & 1,85 & 2,87 & 1,92 & 1,71 & 2,13 & 1,77 \\
\hline$\triangle$ D_P15_PRE & 3,48 & 4,58 & 1,66 & 4,26 & 2,69 & 3,08 & 2,77 & 2,46 \\
\hline$\Delta \_\mathrm{P} 15 \_\mathrm{P} 0$ & 0,06 & 2,68 & 0,17 & 2,70 & 0,78 & 2,53 & 0,98 & 1,93 \\
\hline
\end{tabular}

$M-$ mean value. IQR - interquartile range

Table 3 contains the summary of directions of changes of all the analyzed HRV parameters in response to being tilted to the semi-vertical position, which means PO stage compared to PRE stage. In the POS and NEG groups the response of all HRV parameters to the tilt was similar. In both groups the onset of TT resulted in the decrease of meanRR (which means an increased heart rate), SDNN, RMSSD, pNN50, abs_HF, rel_HF, norm_ HF. The mean values of rel_LF, norm_LF and LF/HF increased, and the value of abs_LF did not change. In the CG_NEG group the values of meanRR, pNN50, abs_HF, rel_HF and norm_HF descreased, norm_LF and LF/HF increased (similarly as in the POS and NEG groups), and the values of SDNN, RMSSD, abs_LF, rel_LF did not change.

We did not observe any significant differences between groups POS and NEG in the values of any of the analyzed HRV parameters, at any stage of TT. Moreover, none of the derivant parameters was significantly dif-
Table 3. Summary of directions of changes of HRV parameters in response to being tilted to the semi-vertical position (during PO stage as compared to PRE)

\begin{tabular}{|c|c|c|c|}
\hline & POS & NEG & CG_NEG \\
\hline meanRR & $\downarrow$ & $\downarrow$ & $\downarrow$ \\
\hline SDNN & $\downarrow$ & $\downarrow$ & - \\
\hline RMSSD & $\downarrow$ & $\downarrow$ & - \\
\hline pNN50 & $\downarrow$ & $\downarrow$ & $\downarrow$ \\
\hline abs_LF & - & - & - \\
\hline abs_HF & $\downarrow$ & $\downarrow$ & $\downarrow$ \\
\hline rel_LF & $\uparrow$ & $\uparrow$ & - \\
\hline rel_HF & $\downarrow$ & $\downarrow$ & $\downarrow$ \\
\hline norm_LF & $\uparrow$ & $\uparrow$ & $\uparrow$ \\
\hline norm_HF & $\downarrow$ & $\downarrow$ & $\downarrow$ \\
\hline LF/HF & $\uparrow$ & $\uparrow$ & $\uparrow$ \\
\hline
\end{tabular}

ferent between those two groups. The results are summrized in table 4. 
Table 4. Summary of the comparative analysis of HRV measures between groups POS and NEG at different stages of tilt table test.

\begin{tabular}{|c|c|c|c|c|c|c|c|c|c|c|}
\hline $\begin{array}{l}\text { TT stage / } \\
\text { derivative } \\
\text { parameter }\end{array}$ & SDNN & RMSSD & pNN50 & abs_LF & abs_HF & rel_LF & rel_HF & norm_LF & norm_HF & LF/HF \\
\hline PRE & ns & ns & ns & ns & ns & ns & ns & ns & ns & ns \\
\hline PO & ns & ns & ns & ns & ns & ns & ns & ns & ns & ns \\
\hline P15 & ns & ns & ns & ns & ns & ns & ns & ns & ns & ns \\
\hline$\Delta \_$PO_PRE & ns & ns & ns & ns & ns & ns & ns & ns & ns & ns \\
\hline$\triangle$ A_P15_PRE & ns & ns & ns & ns & ns & ns & ns & ns & ns & ns \\
\hline D_P15_P0 & ns & ns & ns & ns & ns & ns & ns & ns & ns & ns \\
\hline
\end{tabular}

ns - nonsignificant

No significant differences were observed in HRV values of patients with a history of syncope and a positive or negative result of TT performed according to the Italian protocol. The onset of TT led to changes in values of HRV parameters in the same direction in patients with a positive and negative test result, as well as in patients with no history of syncope and negative test result. No association was found between the direction of reaction or change in numerical values of HRV parameters in response to the onset of TT and the positive or negative test result.

TT performed according to the Italian protocolmay give an unexpectedly high percentage of positive results in patients with no history of syncope or presyncope.

\section{Discussion}

Tilt table test is commonly used for diagnosis of vasovagal syncope [26]. The mechanism of vasovagal syncope is defined, but the direct translation of a trigger into reflex response is unknown [63-64]. For that reason, the mechanisms and course of vasovagal syncope, the parameters of regulatory mechanisms of circulation and parameters that help make definite diagnosis without the use of the TT are subject of on-going research [28-29,65-66].

The occurence of different types of vasovagal response induced during TT varies widely the in available reports: $42-89 \%$ for VVS-1, 0-50\% for VVS-2 and 0-11\% for VVS-3 $[16,67,68]$. In our cohort, the POS group, the distribution is as follows: in $74 \%$ of patients VVS-1 was observed, and VVS-2 in $26 \%$. No cases of VVS-3 may be explained by the young age of patients, and by the fact that patients over 50 years of age were excluded from the study. In the control group there was an unexpectedly high percentage of positive results (14 patients out of 50). In all false positive cases, the vasovagal reflex was observed during the active phase, and VVS-1 was observed. The percentage of 'false positive' TT results in the literature varies from 0 to $30 \%$ [18]. High percentage of positive results in our CG may be explained in several ways: (1) patients may not have identified symptoms of vasovagal reaction in their earlier life (not only syncope/presyncope, but for example orthostatic intolerance or intolerance of medical instrumentation) and therefore their history is 'false negative'; (2) vasovagal reactions may not have appeared earlier, because the mean onset of syncopal events is at 25 years of age [69], and some patients were younger; (3) possible dyssymulation by the patients that wanted to use the occasion to test cardiovascular reactions during the test (volunteers were also recruited among medical university students); (4) some experts claim that vasovagal reactions are normal and common in the general population [17].

Comparison of our results with other available analyses of HRV during TT is difficult, due to the variety of definitions, study groups, endpoints, protocols of TT, sets of analyzed parameters, and rarely one can find more than one study with parameters similar enough to make a comparison.

Despite that difficulty, we made an attempt to compare our results with the available analyses. Our observations are presented together with the data from the literature in tables 5 and 6 . Table 5 contains data regarding time domain parameters, and table 6 - frequency domain. Please note that most of the studies in that comparison had different TT protocols, small study groups and various definitions of study groups.

The potential advantage of our study is that it included a relatively large cohort of patients. Whereas the main potential limitation is that we did not have means to correct HRV measures according to respitratory pattern, nonetheless we used paced breathing to minimize the respiratory bias. The same limitation can also be noted in most of the cited studies. 
Table 5. Comparison of literature data and our observations regarding time domain HRV parameters. $A b b r e v i a t i o n s: S / P(+)-p o s i t i v e$ history of syncope/presyncope; S/P(-) - negative history of syncope/presyncope; TT(+) - positive result of TT; TT(-) - negative result of TT

\begin{tabular}{|c|c|c|}
\hline Paramete & Literature data & Own observations \\
\hline \multicolumn{3}{|c|}{ Pre-test values } \\
\hline meanRR & \begin{tabular}{|l} 
- no differences between study groups \\
{$[41,44,45,48,51]$}
\end{tabular} & - no differences between study groups \\
\hline SDNN & $\begin{array}{l}\text { - no differences between study groups } \\
\quad[38,41,43,44,51] \\
\text { - higher value in } S / P(-), \Pi(-) \text { than } S / P(+)[48]\end{array}$ & - no differences between study groups \\
\hline RMSSD & \begin{tabular}{|l} 
- no differences between study groups [43- \\
$45,48]$
\end{tabular} & - no differences between study groups \\
\hline pNN50 & $\begin{array}{l}\text { - no differences between study groups } \\
{[41,43,44]}\end{array}$ & - no differences between study groups \\
\hline \multicolumn{3}{|c|}{ Values during TT } \\
\hline meanRR & - no data available & - no differences between study groups \\
\hline SDNN & - no data available & - no differences between study groups \\
\hline \multicolumn{3}{|c|}{ Direction of change of the values in response to tilt } \\
\hline meanRR & - no data available & - decrease (POS, NEK, CG_NEG) \\
\hline SDNN & - no data available & - decrease (POS, NEG) or no change (CG_NEG) \\
\hline RMSSD & - decrease in $\Pi(-)$, but not in $\Pi(+)[45]$ & - decrease (POS, NEG) or no change (CG_NEG) \\
\hline pNN50 & - no data available & $\begin{array}{l}\text { - decrease (POS, NEG) or no change (CG_NEG, } \\
\text { CG_POS) }\end{array}$ \\
\hline
\end{tabular}

Tabela 6. Comparison of literature data and our observations regarding frequency domain HRV parameters. Abbreviations: $\mathrm{S} / \mathrm{P}(+)-\mathrm{positi-}$ ve history of syncope/presyncope; S/P(-) - negative history of syncope/presyncope; TT(+) - positive result of TT; TT(-) - negative result of TT

\begin{tabular}{|c|c|c|}
\hline Parameter & Literature data & Own observations \\
\hline \multicolumn{3}{|c|}{ Pre-test values } \\
\hline abs_LF & $\begin{array}{l}\text { - no differences between study groups }[33,41,57,43,46,47 \text {, } \\
49,50,52,54,55]\end{array}$ & $\begin{array}{l}\text { - no differences between study } \\
\text { groups }\end{array}$ \\
\hline abs_HF & $\begin{array}{l}\text { - no differences between study groups }[33,41,57,44,46,47 \text {, } \\
49,50,52,54,55]\end{array}$ & $\begin{array}{l}\text { - no differences between study } \\
\text { groups }\end{array}$ \\
\hline rel_LF & - no data available & $\begin{array}{l}\text { - no differences between study } \\
\text { groups }\end{array}$ \\
\hline rel_HF & - no data available & $\begin{array}{l}\text { - at rest lower values in POS and } \\
\text { NEG than in CG_NEG }\end{array}$ \\
\hline norm_LF & $\begin{array}{l}\text { - no differences between study groups [54] } \\
\text { - lower value in a group similar to POS than in CG_NEG [70] }\end{array}$ & $\begin{array}{l}\text { - no differences between study } \\
\text { groups }\end{array}$ \\
\hline norm_HF & - no differences between study groups $[54,70]$ & $\begin{array}{l}\text { - no differences between study } \\
\text { groups }\end{array}$ \\
\hline $\mathrm{LF} / \mathrm{HF}$ & $\begin{array}{l}\text { - no differences between study groups }[33,43,44,47,55] \\
\text { - lower value in a group similar to POS than in CG_NEG }[70]\end{array}$ & $\begin{array}{l}\text { - no differences between study } \\
\text { groups }\end{array}$ \\
\hline \multicolumn{3}{|c|}{ Values during TT } \\
\hline abs_LF & $\begin{array}{l}\text { - lower increase after tilt in } \mathrm{S} / \mathrm{P}(+) \Pi T(+) \text { than } \mathrm{S} / \mathrm{P}(-)[41] \\
\text { - lower values after tilt in } \mathrm{S} / \mathrm{P}(-) \Pi T(-) \text { than } \mathrm{S} / \mathrm{P}(+) \Pi T(+) \text { and } \\
\mathrm{S} / \mathrm{P}(+) \Pi T(-)[47]\end{array}$ & $\begin{array}{l}\text { - no difference between POS and } \\
\text { NEG }\end{array}$ \\
\hline abs_HF & - higher value after tilt in $S / P(+) T T(+)$ than $S / P(-)[41]$ & $\begin{array}{l}\text { - no difference between POS and } \\
\text { NEG }\end{array}$ \\
\hline rel_LF & - no available data & $\begin{array}{l}\text { - no differences between study } \\
\text { groups }\end{array}$ \\
\hline rel_HF & - no available data & $\begin{array}{l}\text { - no difference between POS and } \\
\text { NEG }\end{array}$ \\
\hline norm_LF & $\begin{array}{l}\text { - no differences between study groups [54] } \\
\text { - higher value after tilt in a group similar to POS than NEG } \\
\text { [55] }\end{array}$ & $\begin{array}{l}\text { - no differences between study } \\
\text { groups }\end{array}$ \\
\hline norm_HF & $\begin{array}{l}\text { - no differences between study groups [54] } \\
\text { - lower value after tilt in a group similar to POS than NEG } \\
\text { [55] }\end{array}$ & $\begin{array}{l}\text { - no differences between study } \\
\text { groups }\end{array}$ \\
\hline LF/HF & - no differences between study groups [55] & $\begin{array}{l}\text { - no differences between study } \\
\text { groups }\end{array}$ \\
\hline
\end{tabular}




\begin{tabular}{|c|c|c|}
\hline \multicolumn{3}{|c|}{ Direction of change of the values in response to tilt } \\
\hline abs_LF & $\begin{array}{l}\text { - increase in } S / P(+) T T(+) \text {, no change in } S / P(+) T T(-) \text {, increase in } \\
\text { S/P(-)TT(-) }[33] \\
\text { - increase in } S / P(-) T T(-) \text {, no change in } S / P(+) T T(+) \text { and } S / P(+) \\
\quad \text { TT(-) [47] } \\
- \text { increase in } S / P(+) T T(+) \text {, decrease in } S / P(-) T T(-)[49,50] \\
- \text { no change }[54] \\
- \text { increase in } T(+) \text { and } T(-)[55,57] \\
- \text { increase in } S / P(+) T T(+) \text {, no change in } S / P(+) T T(-)[57]\end{array}$ & - no change \\
\hline abs_HF & 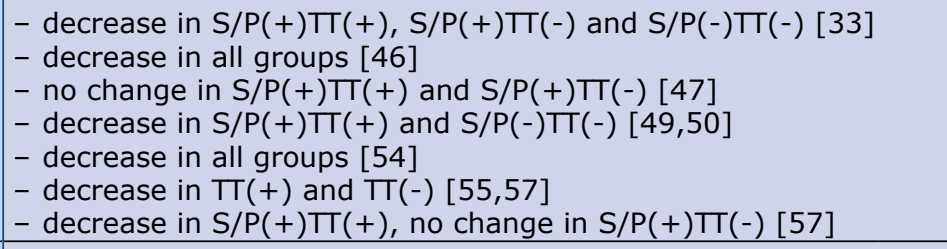 & $\begin{array}{l}\text { - decrease (POS, NEG, } \\
\text { CG_NEG) }\end{array}$ \\
\hline rel_LF & - no available data & $\begin{array}{l}\text { - increase (POS, NEG, } \\
\text { CG_NEG) }\end{array}$ \\
\hline rel_HF & - no available data & - decrease in all groups \\
\hline norm_LF & $\begin{array}{l}\text { - in } S / P(-) T T(+)-\text { increase in some patients, or decrease in the } \\
\text { remaining ones }[39] \\
\text { - increase in all groups }[54,70]\end{array}$ & $\begin{array}{l}\text { - increase (POS, NEG, } \\
\text { CG_NEG) }\end{array}$ \\
\hline norm_HF & $\begin{array}{l}\text { - in } S / P(-) T T(+) \text { increase in some patients, or decrease in the } \\
\text { remaining ones }[39] \\
\text { - decrease in all groups }[54,70]\end{array}$ & $\begin{array}{l}\text { - decrease (POS, NEG, } \\
\text { CG_NEG) }\end{array}$ \\
\hline LF/HF & $\begin{array}{l}\text { - in S/P(-)TT(+) - increase in some patients, or decrease } \\
\text { in the remaining ones }[39] \\
\text { - no change in all groups }[33] \\
- \text { increase in all groups }[46,55] \\
\text { - increase in a group similar to CG_NEG, no change in groups } \\
\text { similar to POS and NEG }[47,49,50] \\
\text { - decrease in a group similar to POS, increase in NEG [52] }\end{array}$ & $\begin{array}{l}\text { - increase (POS, NEG, } \\
\text { CG_NEG) }\end{array}$ \\
\hline
\end{tabular}

\section{Conclusions}

To summarize, the available studies regarding HRV parameters during TT in patients with vasovagal syncope do not form a uniform model of HRV analysis in that clinical setting. In our analysis, HRV parameters did not add any information to traditional hemodynamic monitoring. Specifically, they did not differentiate patients with a positive or negative response to $\mathrm{TT}$, and any attempt to incorporate additional parameters to predict TT response prior to syncope itself seems to be vain. We did not find any studies suitable for a reliable and direct comparison of our data. Taking into account the variability of observed effects in different studies, it would be difficult to draw any conclusions regarding the patophysiological effects based on the analysis of HRV during TT in patients with vasovagal syncope.

\section{References}

1. Moya A, Sutton R, Ammirati F, Blanc J-J, Brignole M, Dahm JB, et al. Guidelines for the diagnosis and management of syncope (version 2009). Eur Heart J. 2009;30(21):2631-2671.

2. Blanc J-J, L'Her C, Touiza A, Garo B, L'Her E, Mansourati J. Prospective evaluation and outcome of patients admitted for syncope over a 1 year period. Eur Heart J. 2002;23(10):815-820.

3. Colivicchi F, Ammirati F, Melina D, Guido V, Imperoli G, Santini M. Development and prospective validation of a risk stratification system for patients with syncope in the emergency department: the OESIL risk score. Eur Heart J. 2003;24(9):811-819.

4. Disertori M, Brignole M, Menozzi C, Raviele A, Rizzon P, Santini M, et al. Management of patients with syncope referred urgently to general hospitals. Eur Eur pacing, arrhythmias, Card Electrophysiol J Work groups Card pacing, arrhythmias, Card Cell Electrophysiol Eur Soc Cardiol. 2003;5(3):283-291.

5. Kapoor WN, Karpf M, Maher Y, Miller RA, Levey GS. Syncope of unknown origin. The need for a more cost-effective approach to its diagnosis evaluation. JAMA J Am Med Assoc. 1982;247(19):2687-2691.

6. Sarasin FP, Louis-Simonet M, Carballo D, Slama S, Rajeswaran A, Metzger JT, et al. Prospective evaluation of patients with syncope: a population-based study. Am J Med. 2001;111(3):177-184. 
7. Calkins H, Byrne M, el-Atassi R, Kalbfleisch S, Langberg JJ, Morady F. The economic burden of unrecognized vasodepressor syncope. Am J Med. 1993;95(5):473-479.

8. Kleinknecht RA, Lenz J. Blood/injury fear, fainting and avoidance of medically-related situations: a family correspondence study. Behav Res Ther. 1989;27(5):537-547.

9. Camfield PR, Camfield CS. Syncope in childhood: a case control clinical study of the familial tendency to faint. Can J Neurol Sci. 1990;17(3): 306-308.

10. Soteriades ES, Evans JC, Larson MG, Chen MH, Chen L, Benjamin EJ, et al. Incidence and prognosis of syncope. N Engl J Med. 2002;347(12): 878-885.

11. Blanc J-J, Benditt DG. Vasovagal Syncope: Hypothesis Focusing on Its Being a Clinical Feature Unique to Humans. J Cardiovasc Electrophysiol. 2016 May;27(5):623-629.

12. Barón-Esquivias G, Pedrote A, Cayuela A, Valle JI, Fernández JM, Arana E, et al. Long-term outcome of patients with asystole induced by headup tilt test. Eur Heart J. 2002;23(6):483-489.

13. Grimm W, Degenhardt M, Hoffman J, Menz V, Wirths A, Maisch B. Syncope recurrence can better be predicted by history than by head-up tilt testing in untreated patients with suspected neurally mediated syncope. Eur Heart J. 1997;18(9):1465-1469.

14. Natale A, Geiger MJ, Maglio C, Newby KH, Dhala A, Akhtar M, et al. Recurrence of neurocardiogenic syncope without pharmacologic interventions. Am J Cardiol. 1996;77(11):1001-1003.

15. Ruiz GA, Peralta A, Gonzalez-Zuelgaray J, Duce E. Evolution of patients with clinical neurocardiogenic (vasovagal) syncope not subjected to specific treatment. Am Heart J. 1995;130(2):345-350.

16. Brignole M, Menozzi C, Del Rosso A, Costa S, Gaggioli G, Bottoni N, et al. New classification of haemodynamics of vasovagal syncope: beyond the VASIS classification. Analysis of the pre-syncopal phase of the tilt test without and with nitroglycerin challenge. Vasovagal Syncope International Study. Europace. 2000;2(1):66-76.

17. Alboni P, Brignole M, Degli Uberti EC. Is vasovagal syncope a disease? Eur Eur pacing, arrhythmias, Card Electrophysiol J Work groups Card pacing, arrhythmias, Card Cell Electrophysiol Eur Soc Cardiol. 2007;9(2):83-87.

18. Bartoletti A, Alboni P, Ammirati F, Brignole M, Del Rosso A, Foglia Manzillo G, et al. "The Italian Protocol": a simplified head-up tilt testing potentiated with oral nitroglycerin to assess patients with unexplained syncope. Eur Eur pacing, arrhythmias, Card Electrophysiol J Work groups Card pacing, arrhythmias, Card Cell Electrophysiol Eur Soc Cardiol. 2000;2(4):339-342.

19. Shinohara T, Ebata Y, Ayabe R, Fukui A, Okada N, Yufu K, et al. Cardiac autonomic dysfunction in patients with head-up tilt test-induced vasovagal syncope. Pacing Clin Electrophysiol. 2014;37(12):1694-1701.

20. Sutton R. The Value of Tilt Testing and Autonomic Nervous System Assessment. Cardiol Clin. 2015;33(3):357-360.

21. Kenny RA, Ingram A, Bayliss J, Sutton R. Head-up tilt: a useful test for investigating unexplained syncope. Lancet. 1986;1(8494):1352-1355.

22. Zyśko D, Fedorowski A, Nilsson D, Rudnicki J, Gajek J, Melander O, et al. Tilt testing results are influenced by tilt protocol. Europace. 2016;18(7):1108-1112

23. Lee AKY, Krahn AD. Evaluation of syncope: focus on diagnosis and treatment of neurally mediated syncope. Expert Rev Cardiovasc Ther. 2016;14(6):725-736.

24. Kim T-H, Jang H-J, Kim S, Cho SY, Song KS, Pickett C, et al. A new test for diagnosing vasovagal syncope: Standing after treadmill test with sublingual nitrate administration. Fukumoto Y, editor. PLoS One. 2017;12(6):e0179631.

25. Chaddha A, Wenzke KE, Brignole M, Wasmund SL, Page RL, Hamdan MH. The Role of the Baroreflex in Tilt Table Testing. JACC Clin Electrophysiol. 2016;2(7):812-817

26. Brignole M, Alboni P, Benditt DG, Bergfeldt L, Blanc J-J, Bloch Thomsen PE, et al. Guidelines on management (diagnosis and treatment) of syncope--update 2004. Eur Eur pacing, arrhythmias, Card Electrophysiol J Work groups Card pacing, arrhythmias, Card Cell Electrophysiol Eur Soc Cardiol. 2004;6(6):467-537.

27. Humm AM, Z'Graggen WJ. Venepuncture during head-up tilt testing in patients with suspected vasovagal syncope - implications for the test protocol. Eur J Neurol. 2015;22(2):389-394.

28. Krauze T, Guzik P, Wysocki H. Zmienność rytmu serca: aspekty techniczne. Now Lek. 2001;70(9):973-984

29. Heart rate variability. Standards of measurement, physiological interpretation, and clinical use. Task Force of the European Society of Cardiology and the North American Society of Pacing and Electrophysiology. Eur Heart J. 1996;17(3):354-381.

30. Sneddon JF, Bashir Y, Murgatroyd FD, Ward DE, Camm AJ, Malik M. Do patients with neurally mediated syncope have augmented vagal tone? Am J Cardiol. 1993;72(17):1314-1315.

31. Sneddon JF, Counihan PJ, Bashir Y, Haywood GA, Ward DE, Camm AJ. Assessment of autonomic function in patients with neurally mediated syncope: augmented cardiopulmonary baroreceptor responses to graded orthostatic stress. J Am Coll Cardiol. 1993;21(5):1193-1198.

32. Kochiadakis GE, Orfanakis AE, Rombola AT, Chrysostomakis SI, Chlouverakis GI, Vardas PE. Reproducibility of time-domain indexes of heart rate variability in patients with vasovagal syncope. Am J Cardiol. 1997;79(2):160-165.

33. Kochiadakis GE, Rombola AT, Kanoupakis EM, Simantirakis EN, Chlouverakis GI, Vardas PE. Assessment of autonomic function at rest and during tilt testing in patients with vasovagal syncope. Am Heart J. 1997;134(3):459-466.

34. Hosaka H, Takase B, Katsushika S, Ohsuzu F, Kurita A. Altered fractal behavior and heart rate variability in daily life in neurally mediated syncope. Biomed Pharmacother. 2003;57 Suppl 1:77s-82s.

35. Takase B, Akima T, Satomura K, Mastui T, Ohsuzu F, Ishihara M, et al. Assessment of autonomic activity during daily life of patients with headup tilt-induced prolonged asystole. Biomed Pharmacother. 2004;58 Suppl 1:S40-44.

36. Cintra F, Poyares D, DO Amaral A, DE Marchi G, Barreto S, Tufik S, et al. Heart rate variability during sleep in patients with vasovagal syncope. Pacing Clin Electrophysiol PACE. 2005;28(12):1310-1316. 
37. Pagani M, Lombardi F, Guzzetti S, Rimoldi O, Furlan R, Pizzinelli P, et al. Power spectral analysis of heart rate and arterial pressure variabilities as a marker of sympatho-vagal interaction in man and conscious dog. Circ Res. 1986;59(2):178-193.

38. Vybiral T, Bryg RJ, Maddens ME, Boden WE. Effect of passive tilt on sympathetic and parasympathetic components of heart rate variability in normal subjects. Am J Cardiol. 1989;63(15):1117-1120.

39. Furlan R, Piazza S, Dell'Orto S, Barbic F, Bianchi A, Mainardi L, et al. Cardiac autonomic patterns preceding occasional vasovagal reactions in healthy humans. Circulation. 1998;98(17):1756-1761.

40. Lipsitz LA, Mietus J, Moody GB, Goldberger AL. Spectral characteristics of heart rate variability before and during postural tilt. Relations to aging and risk of syncope. Circulation. 1990;81(6):1803-1810.

41. Morillo CA, Klein GJ, Jones DL, Yee R. Time and frequency domain analyses of heart rate variability during orthostatic stress in patients with neurally mediated syncope. Am J Cardiol. 1994;74(12):1258-1262.

42. Vardas $P$, Kochiadakis $G$, Orfanakis A, Kalaitzakis $M$, Manios $E$. Intraindividual reproducibility of heart rate variability before and during postural tilt in patients with syncope of unknown origin. Pacing Clin Electrophysiol PACE. 1994;17(11 Pt 2):2207-2210.

43. Baran I, Kaderli AA, Ozdemir B, Gemici K, Ekbul A, Güllülü S, et al. Lack of association of heart rate variability parameters with head-up tilt-test responses in patients with syncope. Indian Heart J. 2004;56(3):229-231.

44. Pruvot E, Vesin JM, Schlaepfer J, Fromer M, Kappenberger L. Autonomic imbalance assessed by heart rate variability analysis in vasovagal syncope. Pacing Clin Electrophysiol PACE. 1994;17(11 Pt 2):2201-2206.

45. Lippman N, Stein KM, Lerman BB. Failure to decrease parasympathetic tone during upright tilt predicts a positive tilt-table test. Am J Cardiol. 1995;75(8):591-595.

46. Prinz-Zaiss M, Yeap AN, Moguilevski V, Trigg L, McGrath BP. Presyncopal sympathetic withdrawal is the same in patients with vasodepressor syncope and controls who faint on head-up tilting. Am Heart J. 1997;133(2):230-239.

47. Kochiadakis GE, Orfanakis A, Chryssostomakis SI, Manios EG, Kounali DK, Vardas PE. Autonomic nervous system activity during tilt testing in syncopal patients, estimated by power spectral analysis of heart rate variability. Pacing Clin Electrophysiol PACE. 1997;20(5 Pt 1):1332-1341.

48. Grimm W, Wirths A, Hoffmann J, Menz V, Maisch B. Heart rate variability during head-up tilt testing in patients with suspected neurally mediated syncope. Pacing Clin Electrophysiol PACE. 1998;21(11 Pt 2):2411-2415.

49. Kochiadakis GE, Papadimitriou EA, Marketou ME, Chrysostomakis SI, Simantirakis EN, Vardas PE. Autonomic nervous system changes in vasovagal syncope: is there any difference between young and older patients? Pacing Clin Electrophysiol PACE. 2004;27(10):1371-1377.

50. Kochiadakis GE, Kanoupakis EM, Igoumenidis NE, Marketou ME, Solomou MC, Vardas PE. Spectral analysis of heart rate variability during tilt-table testing in patients with vasovagal syncope. Int J Cardiol. 1998;64(2):185-194.

51. Guzmán CE, Sánchez GM, Márquez MF, Hermosillo AG, Cárdenas M. Differences in heart rate variability between cardioinhibitory and vasodepressor responses to head-up tilt table testing. Arch Med Res. 1999;30(3):203-211.

52. Kouakam C, Lacroix D, Zghal N, Logier R, Klug D, Le Franc $P$, et al. Inadequate sympathovagal balance in response to orthostatism in patients with unexplained syncope and a positive head up tilt test. Heart. 1999;82(3):312-318.

53. Folino AF, Russo G, Porta A, Buja G, Cerutti S, lliceto S. Modulations of autonomic activity leading to tilt-mediated syncope. Int J Cardiol. 2007;120(1):102-107.

54. Freitas J, Pereira S, Lago P, Costa O, Carvalho MJ, Falcão de Freitas A. Impaired arterial baroreceptor sensitivity before tilt-induced syncope. Eur Eur pacing, arrhythmias, Card Electrophysiol J Work groups Card pacing, arrhythmias, Card Cell Electrophysiol Eur Soc Cardiol. 1999;1(4):258-265.

55. Ruiz GA, Madoery C, Arnaldo F, Menéndez C, Tentori MC. Frequency-domain analysis of heart rate variability during positive and negative head-up tilt test: importance of age. Pacing Clin Electrophysiol PACE. 2000;23(3):325-332.

56. Mangin L, Kobeissi A, Lelouche D, Dhérouville TY, Mansier P, Swynghedauw B, et al. Simultaneous analysis of heart rate variability and myocardial contractility during head-up tilt in patients with vasovagal syncope. J Cardiovasc Electrophysiol. 2001;12(6):639-644.

57. Folino AF, Russo G, Porta A, Buja G, Cerutti S, Iliceto S. Autonomic modulation and cardiac contractility in vasovagal syncope. Int J Cardiol. 2010;139(3):248-253.

58. Suzuki M, Hori S, Nakamura I, Nagata S, Tomita Y, Aikawa N. Role of vagal control in vasovagal syncope. Pacing Clin Electrophysiol PACE. 2003;26(2 Pt 1):571-578.

59. Budrejko S. Analysis of heart rate variability during head-up tilt test in patients with vasovagal syncope. 15th Int Student Sci Conf Students Young Dr Gdańsk. 2007;S244.

60. Klemenc M, Štrumbelj E. Predicting the outcome of head-up tilt test using heart rate variability and baroreflex sensitivity parameters in patients with vasovagal syncope. Clin Auton Res. 2015;25(6):391-398.

61. Gursul E, Bayata S, Tuluce SY, Berilgen R, Safak O, Ozdemir E, et al. Parameters of Heart Rate Variability Can Predict Prolonged Asystole before Head-Up Tilt Table Test. Ann Noninvasive Electrocardiol. 2014 Sep;19(5):477-482.

62. Duplyakov D, Golovina G, Sysuenkova E, Garkina S. Can the result of a tilt test be predicted in the first five minutes? Cardiol J. 2011;18(5): 521-526.

63. Hainsworth R. Syncope: what is the trigger? Heart. 2003;89(2):123-124.

64. Hainsworth R. Pathophysiology of syncope. Clin Auton Res Off J Clin Auton Res Soc. 2004;14 Suppl 1:18-24.

65. Turk U, Alioglu E, Kirilmaz B, Duygu H, Tuzun N, Tengiz I, et al. Prediction of head-up tilt test result: is it possible? Pacing Clin Electrophysiol PACE. 2010;33(2):153-158.

66. Virag N, Sutton R, Vetter R, Markowitz T, Erickson M. Prediction of vasovagal syncope from heart rate and blood pressure trend and variability: experience in 1,155 patients. Hear Rhythm Off J Hear Rhythm Soc. 2007;4(11):1375-1382.

67. Aerts AJ, Dendale P. Nitrate-stimulated tilt test. Am Heart J. 1999;137(3):575-576. 
68. Kurbaan AS, Franzén AC, Bowker TJ, Williams TR, Kaddoura S, Petersen ME, et al. Usefulness of tilt test-induced patterns of heart rate and blood pressure using a two-stage protocol with glyceryl trinitrate provocation in patients with syncope of unknown origin. Am J Cardiol. 1999;84(6):665-670.

69. Chen LY, Shen W-K, Mahoney DW, Jacobsen SJ, Rodeheffer RJ. Prevalence of syncope in a population aged more than 45 years. Am J Med. 2006;119(12):1088.e1-7.

70. Piccirillo G, Naso C, Moisè A, Lionetti M, Nocco M, Di Carlo S, et al. Heart rate and blood pressure variability in subjects with vasovagal syncope. Clin Sci (London, Engl 1979). 2004;107(1):55-61. 